\title{
A Framework for Addressing the Challenges of Business Process Change during Enterprise Systems Integration
}

\begin{abstract}
Purpose- Enterprise Systems Integration (ESI) is necessary for today's business environment to access real-time data and quickly respond to fluctuating market demand. Business Process Change (BPC) as a significant prerequisite of ESI encompasses various challenges that must be tackled by employing success factors, techniques, and approaches. This study focuses on BPC challenges and develops a conceptual framework for addressing BPC challenges in ESI. Design/Methodology/Approach- BPC challenges and their success factors were firstly identified through a literature analysis. Then, the findings from the literature were thematically analysed and qualitatively validated through 35 unstructured interviews for developing the conceptual framework.
\end{abstract}

Findings- The findings from the literature suggested 17 BPC challenge along with their success factors. During the validation process, 15 BPC challenges were accepted by all interviewees, while most of the respondents disagreed with the two challenges of 'consolidation of information system reengineering with BPR', and 'customisation'. Moreover, 'risk' was suggested as a BPC challenge by several interviewees. Thus, the study offered a modified list of BPC challenges that was empirically validated.

Originality/value- The study proposes a conceptual framework for addressing BPC challenges in ESI that enables enterprises to design their systems integration roadmap, based on an understanding of BPC challenges and their success factors; as well as supporting solution providers to develop solutions for effective and efficient BPC. Furthermore, the framework will act as a basis for BPC and developing a similar framework for other related contexts, such as smart cities.

Keywords: Enterprise systems, systems integration, business process change, BPC

Article Type: Research paper

\section{Motivation of research}

Since the 1940s, Enterprise Systems Integration (ESI) has been a crucial goal for enterprises, to improve their performance by sharing data, accessing real-time information, and making decisions on-time (Schubert and Williams, 2011).

An integrated enterprise comprises a number of sub-systems, which seamlessly interact with each other (ISO/EN I9439, 2003 cited in Chen et al., 2008), so that they can be considered as a whole. This capability is achieved by the process of integrating Enterprise Systems (ES), so- 
called ESI, at both information and process levels (Grabot et al., 2008). Hence, ESI is the process of providing seamless intercommunication throughout the sub-systems of an ES.

ESI offers multi-dimensional benefits, which have been highlighted by earlier researchers such as Shang and Seddon (2002) and Hendricks et al. (2007). Nonetheless, it should be emphasised that the main advantage and core capability for enterprises is the integration itself and that is all about access to real-time information by connecting business processes across enterprise departments/sub-systems through the adoption of appropriate technology. Thus, ESI requires a significant change in all ES key elements and addressing the challenges of these aspects. The key elements are process, people, technology, and flow of data among them (Javidroozi et al., 2015). This research concentrates on the process aspect and attempts to address the challenges of Business Process Change (BPC), which is the most significant area for ESI (Javidroozi et al., 2016). Accordingly, BPC is defined as the analysis, redesign, and the improvement of existing processes to achieve a competitive advantage in performance (Harmon, 2019). The success level of BPC depends on the capabilities to consider the dimensions of BPC and address the challenges (Jurisch et al., 2014). To date, the challenges of BPC have been investigated in the ESI context, so that a number of success factors, approaches, and techniques have been suggested by academia and industry. They have also been categorised by earlier researchers, such as Kettinger and Grover (1995); Motwani (2003); and Rosemann and Bruin (2005). However, an aggregated list of BPC challenges in ESI and a conceptual framework that comprehensively represents dimensions, practices, success factors, tools, and techniques to address the BPC challenges in ESI, has not been offered.

This research acknowledges the importance of early identification of the BPC challenges for a successful ESI, their success factors, and their dimensions/categories and aims at developing a conceptual framework for outlining and addressing BPC challenges in ESI. It is crucial for establishing BPC best practices and conducting a successful BPC for systems integration. The conceptual framework can also be adapted or considered as a guideline for developing similar frameworks in other contexts (e.g. smart city development), in which systems integration is essential.

Thus, the research question is what are the BPC challenges during integration of enterprise systems and how they can be addressed? Consequently, the following objectives are addressed by this research:

- To identify the BPC challenges in ESI, along with success factors, techniques, and approaches for them through a literature analysis

- To validate the identified BPC challenges and their success factors in the ESI context

- To develop a conceptual framework based on the above findings 
As literature analysis is the main resource to identify BPC challenges in SCD, the next section of this research discusses the methodology of the research, then the literature analysis' results were provided in section 3. Next, the validation of the findings is offered. Finally, the BPC challenges in ESI are categorised and a conceptual framework is developed.

\section{Methodology}

This is an explorative study, which employed literature analysis to explore BPC challenges in ESI and their practices, success factors, techniques and approaches. Then, the findings were qualitatively validated through 35 unstructured interviews.

As the main movements related to BPC and their challenges started in the 1990s, one of the inclusion criteria to identify the most relevant and useful articles for review were publications between 1990 and 2019. The other inclusion criteria were the studies published in English, peer-reviewed, and are not under review. By applying these inclusion criteria and using the major keywords, including business process change, enterprise systems, systems integration, process change, process change challenges, BPC challenges, and enterprise process change, 283 relevant sources were carefully selected from peer-reviewed journal and conference articles and some popular and most cited books. Significant online databases such as IEEE, Scopus, Science Direct, and Emerald were utilised in this process. Google Scholar was also used to find and access the articles, online libraries, and E-books. The libraries such as Birmingham City University's libraries and the British library have also been used to find some papers and books. In addition, three key factors of reliability, efficiency, and accuracy were considered in reviewing the literature in this study to select the most appropriate and effective sources (Kothari, 2008). Accordingly, the selected literature were fully reviewed to verify if they provide accurate, reliable, detailed, rich, and empirical data that reveal BPC challenges and success factors in ESI.

As a result of the above, out of 283 selected literature that were previously fulfilled the inclusion criteria. After reviewing their abstract, introduction, and conclusion, only 88 studies were recognised as the most relevant and appropriate literature for this study. Thus, these 88 studies were fully analysed. Nevertheless, after analysing 50 publications, identification of a new BPC challenge or a success factor became very infrequent and after reviewing 70 publications no new challenge or success factor was identified. Hence, the saturation point was met. This was tested and justified several times until all 88 literature were analysed. Thus, the completeness of the study on identifying the BPC challenges in ESI was also verified. 
Literature was qualitatively surveyed to identify BPC challenges and some success factors exemplars for them. Overall, five manual approaches were utilised for qualitative data analysis in this study:

- Coding

- Thematic analysis

- Categorisation strategy

- Connecting strategy

- Memo and display

After finding the most appropriate literature, in which BPC challenges in ESI are discussed, the qualitative literature survey was performed by organising literature data, providing a general understanding of BPC challenges in ESI, and generating themes and theoretical concepts for the challenges. As illustrated in Figure-1, this was carried out by employing the first episode of coding and thematic analysis. In this episode, coding was the main technique to break down literature findings, split the segments, which were most relevant to the research questions, and arrange them into various themes. After that, the BPC challenges identified in this episode were compared, and the researcher tried to group similar challenges. 


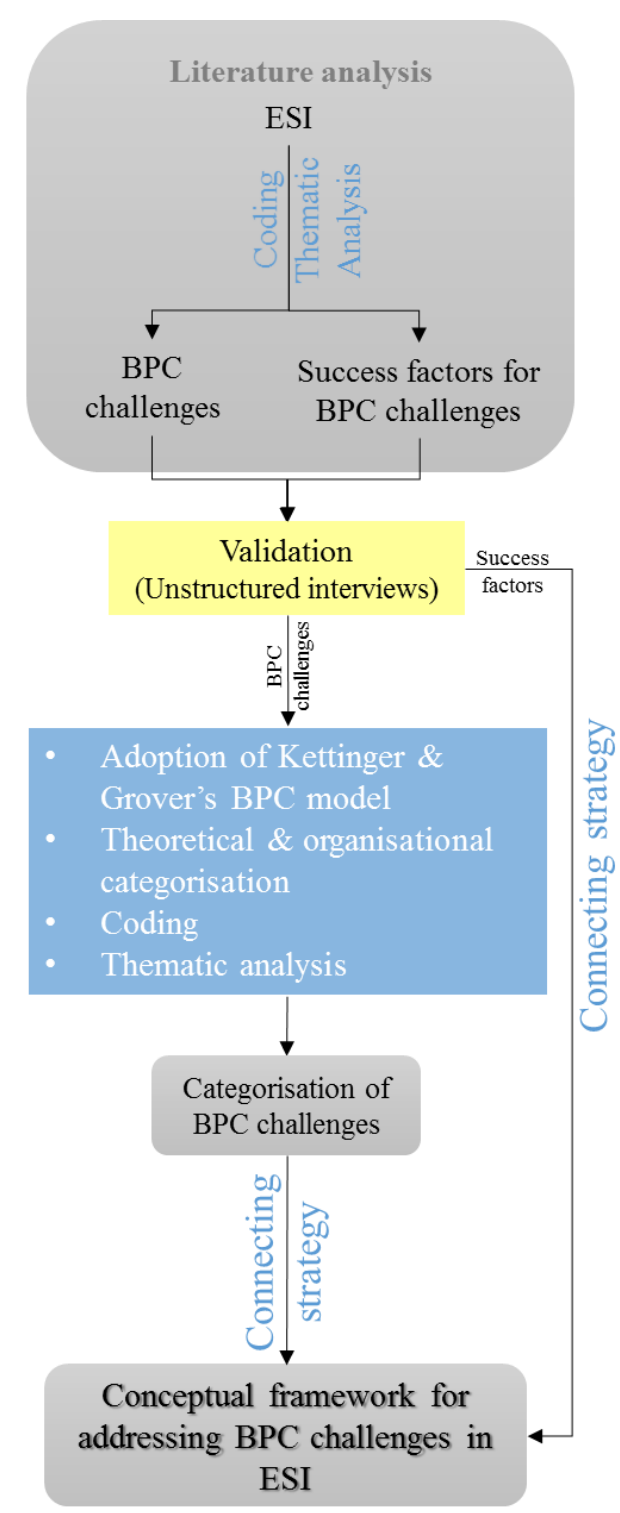

Figure-1: Research methodology diagram

After creating a list of BPC challenges and their success factors, tools, approaches, the list was discussed with participants from organisations, such as SAP, Capgemini, and Atos; through 35 unstructured face-to-face interviews to ensure, based on interviewees' opinion,

- The identified BPC challenges, success factors, tools, techniques, and approaches are valid, and they have been experienced and tested by enterprises;

- The comprehensiveness of the list of identified BPC challenges and their success factors in ESI.

Therefore, the validation began by explaining the research journey in the ESI context. Then, the list of BPC challenges and their success factors was presented and discussed with them based on the following guiding questions: 
- Have you experienced any of the challenges, which are in the list? If so, how you have overcome the BPC challenges? Have you utilised any of the identified success factors?

- Do you agree with all the challenges in the list as BPC challenges, as well as their success factors?

- Have you experienced any BPC challenge, which have been ommitted during the literature analysis?

The participants for validation were selected from two categories:

1. Organisations, in which ESI and BPC has already been conducted

2. Solution providers for ESI and BPC

The inclusion criteria to select interviewees are as follows:

- Directly involved with the ESI projects, especially in BPC phase

- More than two years of experience in changing business processes for ESI

- Fit in project management or implementation role

All interviews were conducted by a face-to-face semi-structured approach. Each semistructured interview was conducted for 45 minutes. In total, the BPC challenges and success factors were discussed with 35 interviewees; 27 of them one-to-one and the rest in groups of two and four. In accordance with the target and saturation point in this research, this is considered to be a sufficient, as after conducting 25 interviews, all BPC challenges and the success factors, identified through literature analysis were verified and no more BPC challenge and success factor was proposed by the interviewees.

The interviews were recorded by taking notes by the researcher and digital audio recording (permission to record the interview was obtained in advance). In the last fie minutes of every interview, the notes taken by the interviewer were double-checked with interviewees to ensure the researcher have understood the participants' answers accurately. After the interviews, all audio records were listened by the researcher several times, and a summary of each of them was created. All audio records were also transcribed by professional transcribers. Next, the transcripts were compared with the summary of audio records, created by the researcher, as well as the notes taken during the interviews. Consequently, a final summary of all findings through interviews was created.

According to the interview findings, several iterations of literature analysis was conducted, the data was modified, and a validated list of BPC challenges and their success factors was offered. Next, for identified BPC challenges in ESI, another thematic analysis episode (as explained 
above for literature analysis) was undertaken. In this episode, two types of categorisation strategies, including organisational and theoretical categorisations were employed.

Firstly, using organisational categorisation (Maxwell, 2008) the researcher anticipated the categories of BPC challenges and prepared them to be studied further. Next, the earlier researchers' categorisations were studied to theoretically modify the anticipated categories. Then, the identified BPC challenges and their success factors, which were related to each category were organised and connected to each category code (Creswell, 2009). Next, another theoretical categorisation was employed to use Kettinger and Grover's (1995) BPC model, which is a comprehensive and reference model for BPC in ESI, as a baseline for this research. The model was analysed, so that the codes generated from descriptions and categories provided by this model, as well as interpretation of the researcher were used to theoretically categorise the BPC challenges in ESI into five categories of managerial, functional, interorganisational, human issues, and environmental. Then, the identified themes/descriptions were interrelated, so that the identified BPC challenges were connected to their categories by interpretation and comparison of their characteristics and themes. Moreover, using this strategy, the success factors were also linked to every BPC challenge. Finally, a conceptual framework for BPC challenges in ESI to represent the BPC challenges, their practices, success factors, as well as some suggested techniques and approaches was developed.

Throughout the qualitative analysis, 'memos', including information that helped to make more sense of data were created and displayed alongside sections of the texts. The importance of this was to summarise and create categories and themes. In addition, some models were designed and displayed to illustrate the relationships and represent data gathered via literature survey and interviews.

Furthermore, In all data coding and analysis phases of this research, including literature and interview transcripts analysis, an 'intercoder reliability' approach was undertaken to ensure reliability and credibility of the data analysis and avoid personal bias. This was carried out by randomly selecting literature findings and interview transcripts to be analysed by an external researcher, and comparing the results with the researcher's analysis.

\section{BPC challenges in ESI and some suggested success factors}

This section provides the result of a literature analysis regarding the BPC challenges in ESI, along with the practice and some exemplar success factors for them.

The next 16 divisions of this section briefly describe the main BPC challenges in ESI that have been commonly discussed by academia and industry. 


\subsection{Clarification and understanding}

For a successful ESI, a sound analysis, assessment, and detailed understanding of business processes before the change are essential, in order to offer a high operational and strategic impact (Fosso Wamba et al., 2018; Scholl, 2004). Also, understanding of how business processes are changed is essential, especially for employees, who will be using those processes in the future (Cochran and Gupta, 2017; Nah et al., 2001). Therefore, this challenge includes clarification and understanding of both existing business processes and BPC. As a result, providing training sessions for employees and involving them to understand business processes and BPC is also required (Dufresne and Martin, 2003). In addition, Dalal et al. (2004) and Momoh et al. (2010) have pointed out that this challenge needs to be tackled by the people who are involved with BPC internally and externally.

These can occur through a Business Process Management (BPM) programme that helps to understand the business requirements, need for change, and the impact of BPC on business (Nah et al., 2001; Dalal et al., 2004; Momoh et al., 2010). Also, several Business Process Modelling (BPMo) techniques and approaches have been proposed by earlier researchers (e.g., Dalal et al., 2004; Xu, 2011; Lodhi et al., 2013) to offer a better understanding of existing business processes and facilitating the next BPC stage depending on the BPC type.

Dalal et al. (2004) reviewed existing BPMo tools and techniques such as Data Flow Diagram (DFD), activity diagram in Unified Modelling Language (UML), and argued that the existing BPMo tools, techniques, and approaches could not overcome the clarification and understanding challenge. They also discussed problems of utilising these methods that represent a need for a theory-based modelling, as well as implementing distributed computing, offering semantics for new process redesign, and establishing a link between business and changing processes.

Also, Legner and Wende (2007) and Xu (2011) pointed out that visualisation of the business process is a significant benefit of choosing an appropriate BPMo technique such as UN/CEFACT's Modelling Methodology (UMM) and RosettaNet to understand current business processes.

Moreover, understanding of business processes has been explained as a significant requirement of BPC by other researchers such as Ferreira and Ferreira (2005) and Liu et al. (2008). They also argued that through collaboration among business processes, BPC would be more understandable and easier to execute. 


\subsection{Efficiency}

Improving the efficiency of business processes is a challenge that should be met during BPC. This is achieved by reducing time lags and redundancies during the integration of business processes across two or more departments or organisations.

While integration itself improves the efficiency of business processes (Swink and Schoenherr, 2015), BPC efficiency can also be improved when an appropriate BMPo approach which is part of BPM system portfolio is selected (Legner and Wende, 2007; Xu, 2011). Other success factors for the challenge include enhancing availability of information, standardisation of business processes, automatic task assignment, and process monitoring provided by Workflow Management System (WfMS) (Xu, 2011). Moreover, appropriateness of the level of BPC with the business processes, capability, and maturity of processes for change, increases the efficiency and effectiveness of BPC. For instance, business process re-engineering (BPR) as a radical change approach for business processes improves efficiency more than other approaches (Rinaldi et al., 2015). Thus, the candidate business processes for BPR should be mature and capable enough for the major change. Also, reducing wasteful activities and waiting times (leads the processes to be more efficient so that it has to be considered in the changing process. Visualisation of business processes by diagrams and BPMo techniques is a way to achieve this (Harmon, 2003, 2019; Slack et al., 2009)

\subsection{Interoperability}

Klischewski (2004) highlights this challenge as the primary goal of business process integration, especially when a business process is carried out by various organisation partners. In other words, an integrated enterprise system is inevitably interoperable (Chalmeta and Pazos, 2015). However, the combination of business process and information integration should be accomplished within a single organisation. Thus, the flow of information between the departments and integration of business processes both are significant for ESI, which can lead to inter-operation and inter-coordination as part of an integrated enterprise (Chen et al., 2008). As a result, enhancing inter-operation and inter-coordination between business processes is a need for integration that requires changing the business processes and creating collaborative business processes (Klischewski, 2004; Liu et al., 2008; Momoh et al., 2010; Xu, 2011).

Guijarro (2007) pointed out that BPC must offer interoperability of new business processes. This can be achieved by providing basic standards and policies to enable a seamless flow of information across different departments, organisations, and administrations; as well as the alignment of administration procedures with technical systems. 
Interoperability has also been signified by several researchers, who have proposed tools, techniques, and approaches to enhance inter-operation and inter-communication between business processes. Workflow Management (WfM) (Legner and Wende, 2007; Xu, 2011), BPM (e.g. Subject-oriented BPM approach (SBPM), some BPMo tools (Liu et al., 2008), Enterprise Application Integration (EAI) (Klischewski, 2004; Xu, 2011), Collaborative Process Management (CPM) approach (Chen and Hsu, 2001), and the step-by-step methodology for improving interoperability, so called the Interoperability Systems Integration and Re-Engineering (IRIS) Framework (Chalmeta and Pazos, 2015) are some examples for maximising interoperability proposed by these investigators.

\subsection{Quality assurance}

An emphasis on quality of BPC as well as redesigned business processes leads to successful systems integration. The quality of BPC should be considered by top management from the beginning of the ESI project, thus visioning and planning for change (as two success factors for ESI) should also include quality management (Nah et al., 2001).

As data sharing is a significant part of BPC across various departments and organisations, improving quality, timeliness, and provision of data also enhances the quality of change towards ESI (Davenport et al., 2004; Xu, 2011; Guo et al., 2014). Moreover, strong management support and understanding integrated business processes as an activity network enhances the quality of BPC. Also, training, user involvement, monitoring, testing and troubleshooting continuously improve the quality of business processes and the changing process (Nah et al., 2001; Finney and Corbett, 2007).

\subsection{Data and process sharing}

Business process sharing is an imperative challenge in both intra-organisational and interorganisational BPC that requires data sharing as well. This challenge can also be the result of the right or wrong assignment of ownership to various parties. Thus, process ownership plays a central role in sharing data and business processes among different partners. In other words, process ownership assignment can be a success factor for data and process sharing in managing BPC (Buh et al., 2015).

In inter-organisational BPC, inter-dependency is higher, and there is no sole owner for business processes so that process ownership would be more challenging. In intraorganisational BPC, the owner is appointed by the leader of the organisation (CEO or Director), to design, use resources, ensure an on-going high-performance, and change the business process as necessary. The business process owner should also be motivated and have authority to get all concerned departments and organisations to carry out the BPC and share 
appropriate data, as necessary. The approach to change and design the business processes should have the capability to align the business processes across organisational boundaries to manage the relationships between business process partners, enabling them to share their data at data level and their activities to fulfil business processes at transitional level (Hammer and Champy, 1993; Liu et al., 2008).

Hvolby and Trienekens (2010) relate this challenge to human issues and state that the culture of business process performers should be changed towards process ownership, to address the data and process sharing challenge.

\subsection{Monitoring}

Business process monitoring and controlling secure a competitive advantage for business process partners (Larsen and Klischewski, 2004). Moreover, monitoring and measuring of the value resulting from all the steps of ESI including BPC are essential to understand and realise the benefits gained from them. It has to be carried out in all phases of systems integration including post-implementation phase (Finney and Corbett, 2007; Momoh et al., 2010). Davenport et al. (2004) suggest that we need to allocate people for realising, monitoring, and measuring the benefits of change.

Control in BPC is one of the critical challenges that need to be addressed by top management support. Also, BPM as an umbrella including several tools and techniques for addressing many BPC challenges helps monitoring of the BPC projects. Monitoring, as an important stage in all BPM lifecycles, is conducted by enhancing controllability of business processes during the change through the integration of human activities with BPM (Liu et al., 2008; Hull and Motahari Nezhad, 2016; Hernández González et al., 2019).

Dufresne and Martin (2003) also suggested BPMo as a framework for controlling and measuring of business processes to assist optimisation of the business processes for the change. Testing and troubleshooting also supports the monitoring and tracking of the changes and identifying errors at very early stages (Nah et al., 2001; Finney and Corbett, 2007).

\subsection{Inter-dependencies}

In an integrated enterprise, the business processes are mainly fulfilled by two or more autonomous departments. However, there are some necessary interdependencies amongst these departments' business processes (Chen et al., 2008; Lodhi et al., 2013; Smeds et al., 2015). Larsen and Klischewski (2004) argue that inter-dependencies reduce the ability of business units/organisations for BPC, because more challenges especially regarding human issues can arise. Thus, managing the relationships between the involved departments is 
essential. In addition, the level of quality, efficiency, and interoperability of innovative processes should not be lowered.

Minimising redundancies and maximising transparency and efficiency across various departments during designing new business processes as well as enhancing inter-operation and inter-coordination between processes and departments (Liu et al., 2008; Momoh et al., 2010). Furthermore, inter-dependencies between business processes, departments, stakeholders, and applications exacerbates some of the challenges, such as complexity (Lodhi et al., 2013) and confidentiality between different partners (Chen and Hsu, 2001), which are accomplished by various partners in different organisations/enterprises. Thus, these challenges should be fulfilled to address the 'inter-dependencies' challenge.

\subsection{Consolidation of IS Reengineering with BPR (BP\&ISR)}

Changing business processes often involves redesigning the information systems and information technologies (IS/IT). Thus, it is recommended that changing IS/IT and business processes should be consolidated and feeding off each other (Weerakkody \& Currie, 2003). To address this challenge, the process participants and IS/IT users should be involved in the reengineering work (Stickland, 1996). In addition, the following success factors should be employed to address this challenge (Weerakkody \& Currie, 2003):

- Management commitment

- Managing the risks associated with business and IS/IT change

- Team work between business and IS/IT people Managing employees' culture and attitude Reducing bureaucracy within functionally oriented organisations

- Developing a framework for integrating BP\&ISR

\subsection{Economic condition and cost of change}

As stated by Herath \& Gupta (2013), business processes are a set of activities that lead to increased costs. Moreover, business process change is itself the main feature of systems integration that causes costs. However, customers, products, and services create the demand for BPC activities. In addition, Kettinger and Grover (1995) pointed out that economic condition is a strategic driver of BPC, which promotes or discourages undertaking BPC activities. Thus, this challenge significantly depends on the control over the resources to utilise them for BPC in an appropriate way (Jurisch et al., 2012).

Cost reduction is an important aim in different types of BPC including business process improvement, optimisation, and re-engineering (Hvolby and Trienekens, 2010; Herath \& Gupta, 2013; Lohrmann and Reichert, 2016). Nonetheless, reduction of cost also challenges 
BPC. This challenge depends on successfully addressing the other issues of BPC (Vergidis et al., 2008). For instance, when the business processes and the changes have been appropriately analysed, understood, monitored, and continuously improved, the cost will be reduced. This can be carried out by a structured approach of BPM (Jarrar et al., 2000; Xu, 2011). Herath \& Gupta (2013) has also suggested a management accounting tool, which is called Activity Based Costing $(\mathrm{ABC})$ framework to understand and provide cost structure and establish linkages between costs in all BPC stages.

In general, fulfilling the other challenges in BPC would also bring a reduction in cost, while optimising the cost of BPC and business processes rarely brings success factors for other challenges (Lewis and Slack, 2003). Furthermore, as one of the most important benefits of any ESI project (such as ERP system implementation) is cost reduction (Fosso Wamba et al., 2018), it should be noted that the investment on BPC will be returned, when ESI project is fully and appropriately executed.

\subsection{Governance}

Optimising governance is the main challenge of BPC management. Governance is a serious challenge especially when the organisations are going to change their business processes. In other words, governance means how an organisation sets, conducts, assesses, and manages the business processes to achieve their goal. It also refers to how an enterprise monitors and reduces the risk (Markus and Jacobson, 2010, 2015; Vom Brocke and Mendling, 2018).

As stated by Braganza and Lambert (2000), governance would be more challenging, when the business processes are cross-functional, and various departments or external organisations are involved, because each department/organisation has their own governance structures and policies for business processes. Thus, the role of governance during BPC for systems integration is more significant, as the business processes are changed with the aim to become more inter-departmental.

To enhance the effectiveness of governance in BPC, the needs of internal and external stakeholders from all departments and organisations should be explicitly recognised. Also, managers should coordinate and balance the mode of governance for each business process. Then, an overall governance profile for each business process across different systems should be established. Most of the business process governance frameworks (for example frameworks developed by Korhonen (2007) and Paim and Flexa (2011)) suggest that clarification of business strategy, goal, and the expectation(s) of enterprise from any particular business process are significant success factors for optimising governance during BPC. 


\subsection{Autonomy and Confidentiality}

Autonomy of various partners (who are legally and functionally independent) in performing the business processes as well as the confidentiality of the activities and sub processes within them create a barrier in converting individual business processes to cross-departmental (interorganisational) processes (Hvolby and Trienekens, 2010; Guo et al., 2014).

Decoupling of inter-organisational (external) and individual (internal) business processes is useful in resolving autonomy and confidentiality challenge. Also, similar to process sharing, WfM, BPMo, and B2B frameworks can help to address the autonomy challenge (Legner and Wende, 2007).

Ensuring the concerned departments/organisations about obtaining their own business objectives and achieving benefit from BPC, establishing trust amongst external partners and assuring them about their privacy and security throughout the process of change, as well as in performing collaborative business processes after the change are the factors that help addressing autonomy and confidentiality challenge (Smith and Fingar, 2006; Liu et al., 2008).

\subsection{Customisation}

Avoiding the use of standard business processes in ESI (e.g. ERP implementation) and increasing customisation is a BPC challenge that can also cause other challenges such as cost and human issues. Therefore, organisations should implement the change with minimum customisation (Holland et al., 1999). This can be achieved by BPMo tools to align the existing business processes to the standard ones. In addition, the most appropriate BPC approach should be utilised before employing IS/IT (Nah et al., 2001).

\subsection{Standardisation}

In this research, standardisation is discussed in two aspects, that is functional (for standardisation of business processes) and managerial (compliance of BPC with business standards, policies, and regulations).

Standardisation of business processes is one of the most imperative requirements of integration, primarily due to the massive change required in business processes (Trkman, 2010). Standardisation is an operational driver of BPC in ESI, so that the success or failure of an integration project depends on how an organisation standardises the business processes according to the requirements of ESI enabler, which is normally a software application (A1Mashari et al., 2003; Morton and Hu, 2008). Hence, BPC should have the ability to standardise business processes (Davenport et al., 2004; Ehie and Madsen, 2005; Xu, 2011). 
Rosenkranz et al. (2010) believe that whether a business process should be standardised during BPC, or not, relies on the nature of that particular business process. For example, non-routine business processes are less likely to be standardised than routine processes. They have also suggested the following factors for standardisation that should be precisely defined and accomplished:

- Focus of standardisation

- Features of business processes, which are candidate for standardisation

- The maturity of business processes

- Purpose of standardisation

- Management of standardisation

- Level of detail of standardisation

- Level of effort for standardisation

- Involvement of end users

- Top management support / Strategic commitment

- Selection of an appropriate BPMo technique

- Experience of team members in standardisation project

- Complexity of standardisation

- Scope of standardisation

Furthermore, BPC should align with business standards, policies, and regulations. Therefore, the BPM approach that is used for BPC should include the BPMo languages (such as WSBPEL and BPMN), which are being adopted as industry standards. In addition, the real-world business policies and standards should be computerised and integrated with BPM, so that the process of BPC would be aligned with them (Liu et al., 2008).

However, there is always a tension between standardisation and flexibility associated with BPC. Therefore, despite the importance of standardisation, organisations should be worried about over standardisation, since it lowers flexibility and innovation (Trkman, 2010, de Albuquerque and Christ, 2015).

\subsection{Agility and flexibility}

The main reason for integration is to provide an environment within an enterprise that rapidly responds to the constant internal and external changes. Thus, business processes should be flexible to adapt to change and be agile to do it quickly. Then, the organisations would have the ability to change their business processes repeatedly, quickly, and economically. This agility also helps the organisations to maintain the quality of change (Lee et al., 2003; Shaw et al., 2007; Liu et al., 2008; Weißbach et al., 2017). Enterprises should also avoid over 
standardisation to provide enough flexibility for business processes. In fact, enterprises should recognise key business processes for BPC, and determine those which should be standardised, and those that are flexible for continuous change. Thus, a balance between standardisation and flexibility of business processes in BPC is suggested (Trkman, 2010).

Agility and flexibility are also key to competitive advantage in the fast-growing business environment. Technical and behavioural integration is required to achieve flexibility and agility. Utilising technical aspects such as software and hardware are the easiest part, while behavioural aspects is the most significant challenge that needs to be addressed by communication, cooperation, and coordination of human factors (Lee et al., 2003).

Shaw et al. (2007) have combined different technologies and modelling techniques and have suggested an architecture for BPMS, to address the challenges of flexibility and agility in BPC. This architecture comprises subject-modelled and the model information system links. Each link includes some blocks (such as model abstraction, formal modelling notation, software language, software application) that aggregate, design, and maintain business processes in a flexible and agile manner.

As stated by $\mathrm{Xu}$ (2011), a combination of EAI, SOA, and BPM can provide agility for BPC and flexibility for functional integration. EAI is useful especially when the current applications and legacy systems continue to provide services during the changing process. Also, SOA breaks the applications into individual functions and processes as services that can be used by other functions and systems within or between enterprises to create new applications. This approach provides agility for business processes to respond to constant and rapid changes in supply chain environment.

\subsection{Complexity}

Organisational change including changing business processes is a complex task that should be comprehensively addressed (Shaw et al., 2007; Momoh et al., 2010). In addition, the business processes in large organisations are complex and BPC approaches are meant to handle this complexity (Shaw et al., 2007; Gureva et al., 2016). However, changing, integrating, and aligning business processes with enterprise systems is also complex (Xu, 2011). Thus, complexity is one of the major challenges in BPC (Scholl, 2004).

As argued by Momoh et al. (2010), understanding organisational issues associated with complexity (such as roles and responsibilities, management capability, management behaviour, and training) is more important than technical aspects.

Literature suggests that factors such as decoupling of BPC in inter-organisational business processes (Legner and Wende, 2007), addressing the challenges of inter-dependency between 
business processes, stakeholders, involved elements, attributes, and applications from BPC in individual processes (Lodhi et al., 2013) opinion, reduces the complexity of BPC.

\subsection{Politics}

Kettinger and Grover (1995) argued that political factors are strategic drivers of BPC, which promote or discourage BPC being carried out. This research considers this factor as a challenge that should be assessed and addressed before and during BPC.

Knights and McCabe (1998) also analysed the political factors in a radical approach to BPC. They believe that BPR itself is political and if politics are not considered in BPC, the change will not happen. Thus, enterprise politics are not irrational and marginal activities. Sturdy (2010) agreed with Knights and McCabe (1998) and stated that political factors are imperative factors for change failure and should not be underestimated. Political guidelines, governmental legislations, bureaucratic principles, and affiliation of the enterprise with political entities are some examples that make the BPC more challenging, especially for large and global enterprises (Grover and Kettinger, 1995; Jurisch et al., 2012).

In general, politics can be productive or disruptive. Addressing the political challenges implies that the organisations should take on board the positive aspects instead of avoiding it altogether, especially the BPC implementers should proactively manoeuvre BPC steps by taking any available political nature (even if they are very basic) into account (Knights and McCabe, 1998; Müller et al., 2017). Recognition of the reservations of stakeholders and decision makers is one of the success factors in addressing this challenge. The managers should also obtain guarantees regarding the support and compliance of these people, perhaps by initiating the change in a top-down approach to ensure political support and feasibility. Therefore, in addition to decision makers, managers should also comply with and support BPC (Jurisch et al., 2012). However, management commitment alone would not suffice for addressing this challenge. Factors such as appreciation of organisational power, as well as the communications between staff, management, and the BPC project manager, would encourage understanding the political aspects of the enterprise (Knights and McCabe, 1998).

\subsection{People related challenges}

These challenges are widely discussed because the role of people is significant in all facets of systems integration including BPC (Jarrar et al., 2000).

For a successful BPC, it is important to establish the change implementation team from the most knowledgeable and skilled people within the organisation (Momoh et al., 2010), because BPC managers and implementers are involved with human issues in many challenging areas 
of BPC, such as complexity, monitoring, agility, flexibility, and politics. The role of people is manifested from the start to the end of the systems integration project so that addressing people related challenges in BPC would facilitate the efforts for overcoming other challenges. Hence, people play a central role in BPC for systems integration (Grover et al. 1995; Nah et al., 2001; Paris \& Thijs, 2003).

BPC challenges from the people perspective comprise many challenges such as commitment to the change, culture changing, resistance to change, and so forth. People related challenges have been considered in Kettinger and Grover's (1995) BPC model in four aspects of values, skills, culture, and behaviours. Table-1 represents some significant examples of people related challenges in BPC.

Table-1: People related BPC challenges

\begin{tabular}{|l|l|}
\hline \multicolumn{1}{|c|}{ Human issues } & \multicolumn{1}{c|}{ Reference } \\
\hline Culture change & $\begin{array}{l}\text { Jarrar et al. (2000), Vaughan (2001), Scholl (2004), } \\
\text { Momoh et al. (2010), Puth \& Walt (2012), Omidi } \\
(2016)\end{array}$ \\
\hline Commitment & $\begin{array}{l}\text { Jarrar et al. (2000) Vaughan (2001), Nah et al. (2004), } \\
\text { Momoh et al. (2010) }\end{array}$ \\
\hline $\begin{array}{l}\text { People acceptance / Resistance to } \\
\text { change }\end{array}$ & $\begin{array}{l}\text { Jarrar et al. (2000), Vaughan (2001), Nah et al. (2004), } \\
\text { Momoh et al. (2010), Pereira et al. (2019) }\end{array}$ \\
\hline Knowledge \& Skills & Kettinger and Grover (1995), Kamal et al. (2013) \\
\hline Relationships & Vaughan (2001), Momoh et al. (2010) \\
\hline $\begin{array}{l}\text { Compatibility between people and } \\
\text { technology }\end{array}$ & Momoh et al. (2010), Madni (2011) \\
\hline Slow decision making under pressure & Madni (2011) \\
\hline
\end{tabular}

\section{Research synthesis}

After identifying the BPC challenges and their success factors through literature analysis, they were qualitatively validated and categorised, in order to develop a conceptual framework for the purpose of the research. These two prerequisites are discussed in the two next sections:

\subsection{Qualitative validation of the identified BPC challenges}

Interviews were undertaken to validate the challenges and success factors through an iterative process, which included revisiting the literature to refine and improve the quality of existing data with the aim to achieve a comprehensive and precise list of BPC challenges and their success factors. In addition, the aim of this validation was to gather the respondents' opinions based on their experience in BPC to assess the challenges and their success factors, identified through the previous phase of research.

Table-2 illustrates the interviewees' roles in relation to BPC in their organisations. 

Table-2: Detail of interviewee roles

\begin{tabular}{|c|c|c|c|c|c|c|}
\hline Interviewees & $\begin{array}{c}\text { Senior } \\
\text { Vice } \\
\text { President }\end{array}$ & $\begin{array}{c}\text { Founder } \\
\text { and } \\
\text { Director }\end{array}$ & $\begin{array}{c}\text { Business } \\
\text { Process } \\
\text { Analyst }\end{array}$ & $\begin{array}{c}\text { Executive } \\
\text { board } \\
\text { member }\end{array}$ & $\begin{array}{l}\text { Business } \\
\text { Planner }\end{array}$ & $\begin{array}{c}\text { Change } \\
\text { manager }\end{array}$ \\
\hline Interviewee-1 & - & - & $\checkmark$ & - & - & $\checkmark$ \\
\hline Interviewee-2 & - & - & - & - & $\checkmark$ & $\checkmark$ \\
\hline Interviewee-3 & - & - & $\checkmark$ & - & - & - \\
\hline Interviewee-4 & - & - & - & - & - & $\checkmark$ \\
\hline Interviewee-5 & - & - & $\checkmark$ & - & - & - \\
\hline Interviewee-6 & - & - & $\checkmark$ & - & - & $\checkmark$ \\
\hline Interviewee-7 & - & - & - & - & - & $\checkmark$ \\
\hline Interviewee-8 & - & - & - & - & $\checkmark$ & $\checkmark$ \\
\hline Interviewee-9 & - & - & $\checkmark$ & - & $\checkmark$ & - \\
\hline Interviewee-10 & - & - & - & - & $\checkmark$ & $\checkmark$ \\
\hline Interviewee-11 & - & - & $\checkmark$ & - & - & $\checkmark$ \\
\hline Interviewee-12 & - & - & $\checkmark$ & - & - & - \\
\hline Interviewee-13 & $\checkmark$ & - & $\checkmark$ & - & - & - \\
\hline Interviewee-14 & - & - & $\checkmark$ & - & - & - \\
\hline Interviewee-15 & - & $\checkmark$ & $\checkmark$ & $\checkmark$ & $\checkmark$ & $\checkmark$ \\
\hline Interviewee-16 & $\checkmark$ & - & - & - & - & $\checkmark$ \\
\hline Interviewee-17 & - & - & - & - & - & $\checkmark$ \\
\hline Interviewee-18 & - & $\checkmark$ & - & - & $\checkmark$ & - \\
\hline Interviewee-19 & - & - & - & $\checkmark$ & - & - \\
\hline Interviewee-20 & - & - & $\checkmark$ & - & - & - \\
\hline Interviewee-21 & - & $\checkmark$ & $\checkmark$ & - & - & - \\
\hline Interviewee-22 & - & - & $\checkmark$ & - & - & $\checkmark$ \\
\hline Interviewee-23 & - & - & - & - & - & $\checkmark$ \\
\hline Interviewee-24 & $\checkmark$ & - & - & - & - & $\checkmark$ \\
\hline Interviewee-25 & - & - & - & - & - & $\checkmark$ \\
\hline Interviewee-26 & - & - & - & $\checkmark$ & - & - \\
\hline Interviewee-27 & - & - & $\checkmark$ & - & - & $\checkmark$ \\
\hline Interviewee-28 & - & - & - & - & - & $\checkmark$ \\
\hline Interviewee-29 & - & - & - & - & - & $\checkmark$ \\
\hline Interviewee-30 & - & - & - & - & - & $\checkmark$ \\
\hline Interviewee-31 & $\checkmark$ & - & - & - & $\checkmark$ & $\checkmark$ \\
\hline Interviewee-32 & - & - & $\checkmark$ & - & - & - \\
\hline Interviewee-33 & - & - & $\checkmark$ & - & - & - \\
\hline Interviewee-34 & - & - & $\checkmark$ & - & - & - \\
\hline Interviewee-35 & - & - & $\checkmark$ & - & - & - \\
\hline
\end{tabular}

To summarise the interview findings, most of the respondents strongly expressed that the list of BPC challenges and their success factors to be comprehensive and clear and takes into consideration all aspects of BPC for ESI. Additionally, it was suggested that developing a framework based on these findings would be a valuable guide for ESI. For example, a respondent said:

'It is very comprehensive and well organised analysis of different indicators for what helps the enterprises to implement their change and be aware of the challenges that they might face...'.

Another respondent commented: 
'Such a framework should be available for decision makers of enterprises before starting their systems integration and process change projects. Project managers shouldn't blindly conduct systems integration without considering such a comprehensive list of BPC challenges and their techniques. This framework especially if adopted for public organisations will be quite useful, as it would provide an insight to what sort of issues might be faced during their projects... '

Although all the respondents found the analysis of identified BPC challenges valuable and beneficial for developing a framework for BPC in ESI, they suggested that the contents and success factors can be improved by innovative tools, techniques, and success factors in the future which will become standard, which can be adopted for any organisation in the private and public sector.

Nevertheless, a few participants mentioned 'risk' as a BPC challenge, which has not been listed. They suggested adding this challenge to the list. No more BPC challenge was offered by the interviewees, but many participants suggested removing 'customisation' and 'BP\&ISR'. They believe that in ESI, customisation is an option when enterprises are not willing to change their business processes. Instead, they prefer to customise standard and predefined business processes, which have been developed based on best practices. Therefore, it is a challenge for the overall ESI project, so it should not be counted as a BPC challenge. Accordingly, one interviewee commented:

'We have implemented integration solutions for enterprises a lot. During changing their processes, we are always dealing with the challenges listed here, but we have never faced customisation as a challenge and in my opinion I don't see it as a BPC challenge. It would definitely provide more value for an enterprise, if required; but generally it cannot be listed as a BPC challenge, in my opinion'.

Similarly, many participants argued that BP\&ISR is an obvious requirement of ESI, meaning that changing business processes and employing IS/IT as an enabler simultaneously can be a success factor for ESI.

These suggestions confirmed the challenging areas of BPC in ESI. The comments also justified the applicability and benefits of the identified BPC challenges and success factors for developing a framework for BPC in ESI. Hence, based on the participants' views and suggestions, several iterations of literature analysis, especially regarding 'risk', 'customisation', and 'BP\&ISR' occurred. The iterations of the literature suggested that many researchers have not emphasised the challenges of customisation and BP\&ISR as a key BPC challenge in ESI, and it is only a way of applying IS/IT to businesses to enable BPC. However, 'risk', especially the propensity of taking risk was considered by some researchers. The 
tendency of risk taking is useful for identification of radicalness of the change and selection of the change approach.

Consequently, avoiding risk lowers the change level (Kettinger and Grover, 1995; Kettinger et al., 1997; Ritchie and Lewis, 2003a). It is also emphasised that various success factors can help in managing the risk of BPC. For example, Kobayashi et al. (2003) claim that changing the business processes step by step, as well as understating and implementing every activity in each step will mitigate the risk. Moreover, effective risk management, integrated with BPM in managing the BPC is significant to address this BPC challenge. Many frameworks and guidelines for risk management have been developed by earlier researchers such as Grabowski and Roberts (2006) and Carey (2001). Na Ranong and Phuenngam (2009) summarised all of these frameworks and guidelines and proposed the following critical success factors for managing risk during BPC:

- Commitment and support from top management

- Communication between the employees, managers, and leader

- The culture of the staff to generate new ideas and solutions, and share their knowledge

- An organisational structure with a view to support, guide, and conduct the enterprise to the change

- Training to improve the organisation members' expertise and knowledge and ensure that they are comfortable with the new business process and understand the integration within the ES

- IT, which is necessary for effective communication and data sharing

- Trust, which encourages the organisations' people to accept and focus on the change

Therefore, based on the interviewees' suggestions the list of BPC challenges and their success factors was modified and utilised to categorise the BPC challenges and to develop a conceptual framework, which is explained in detail in the next section.

\subsection{Categorisation and developing a conceptual framework for addressing BPC challenges in ESI}

Analysing the existing categorisations provided by earlier researchers shows that most of them either provide limited categories/dimensions for BPC (e.g. Jurisch et al.'s (2012) model, which concentrates on managerial, organisational, technological, and human dimensions of BPC) or focus on a particular approach, technique, or tool. For example, Rosemann and Bruin (2005) offer a BPM model, which is limited to strategic, governance, methodological, technological, and people aspects. However, Kettinger and Grover's (1995) BPC model provides a more 
comprehensive view of BPC dimensions (Figure-2). Also, this BPC model has become a reference model for developing a framework for BPC and ESI. Some examples are listed as follows:

- To develop a BPC framework for lean manufacturing (Motwani, 2003)

- To design a BPC framework for examining the implementation of six sigma (Motwani et al., 2004)

- To build a framework for critical success factors of integrating the enterprise systems by ERP (Motwani et al., 2005)

- To develop an integrated framework for IT-enabled BPC (Jurisch et al., 2012)

- To identify the required capabilities for successful BPC (Jurisch et al., 2014)

- To propose a model for organisational elements alignment with BPC implementation (Sikdar and Payyazhi, 2014)

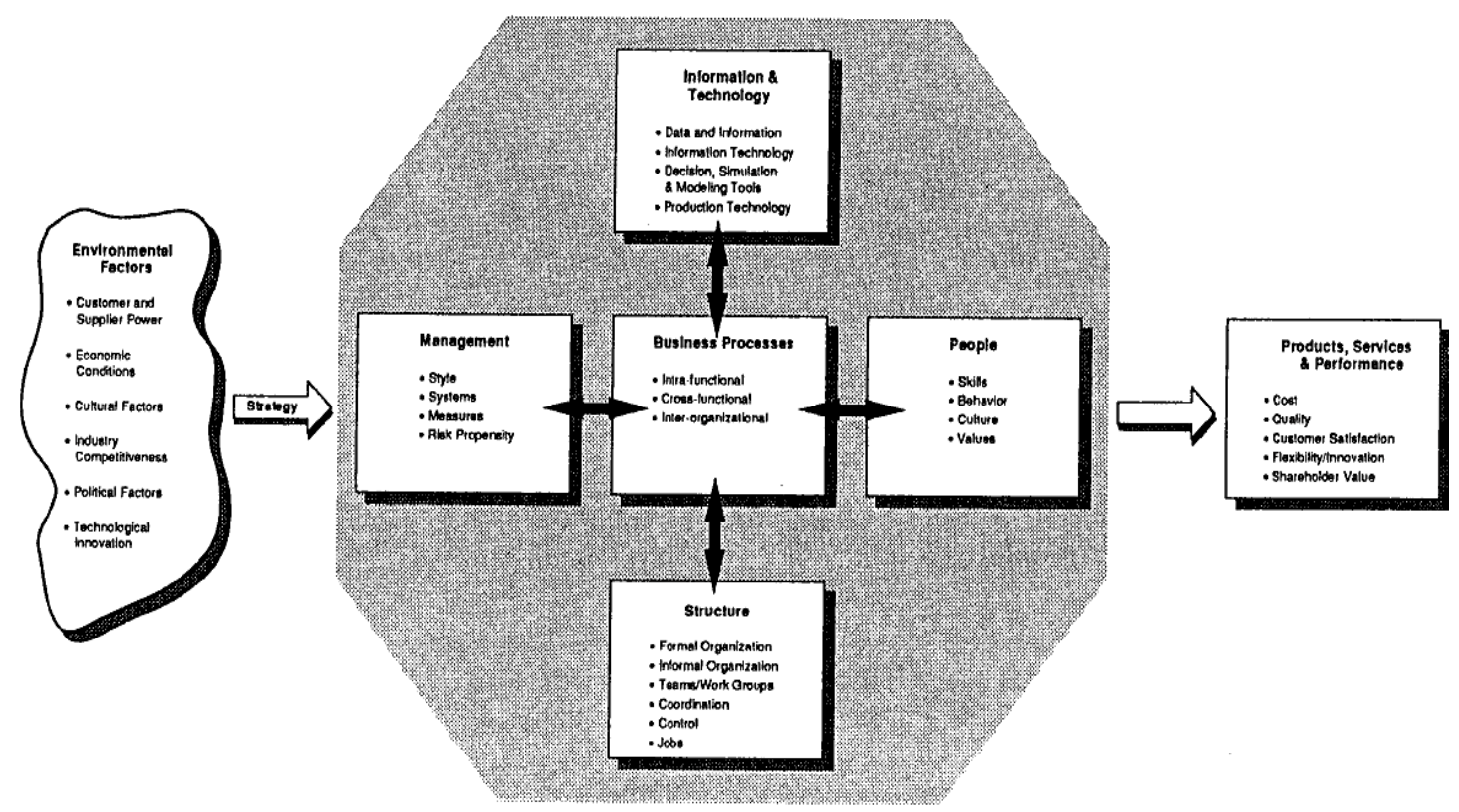

Figure-2: BPC model (Kettinger and Grover, 1995)

According to Kettinger and Grover's (1995) model, BPC is categorised into four dimensions:

- People

- Information \& technology

- Management

- $\quad$ Structure

Each of these categories includes many BPC challenges and some of them are mentioned in the model. 
This research uses Kettinger and Grover's (1995) BPC model as a baseline to propose a new categorisation for the BPC challenges. Thus, the following changes were made to Kettinger and Grover's (1995) categorisation:

- As the challenges mentioned under the structure dimension are related to management, people, and their relationships, they can also be classified in the existing management, and people dimensions, so that this research distributes structural challenges to management and people categories;

- Two more categories, functional and inter-organisational, can be extracted from this BPC model, as they have been mentioned within business processes' block. As many BPC challenges can be classified into these two dimensions, they are considered as separate categories;

- Two more dimensions are not considered as dimensions of BPC, as follows:

- Environmental, which is related to a strategy that leads enterprise to BPC

○ Product, services, performance, which are related to the achievements that enterprises gain after BPC

However, their impact on BPC efforts can be realised by looking at the challenges that have been mentioned by Kettinger and Grover (1995) under these two categories such as politics, economic conditions, technology innovations, cultural factors;

- As this research focuses on process-related challenges, thus the technology dimension is not taken into account and information related challenges will be classified in other categories; and

- The focus of this research does not cover all people related challenges in detail, but because of their importance in all areas of ESI, some of them are briefly discussed, and they are classified in a category called human issues.

As a result, apart from the human issues category, this study categorises BPC challenges into four more categories (Figure-3):

- Managerial (including Kettinger and Grover's structure category)

- Inter-organisational

- Environmental

- Functional 


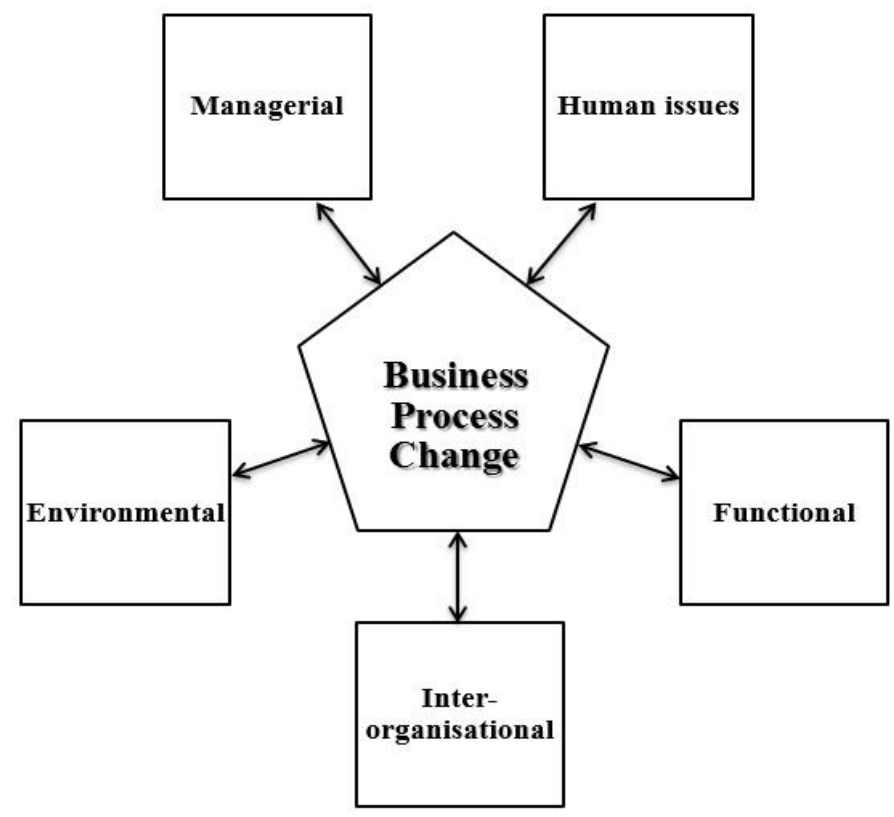

Figure-3: BPC model, representing the categories/dimensions of BPC challenges in this research

Hence, based on the above categories, BPC challenges in ESI, which were identified in this research, are mapped and classified in each category/dimension, shown in Table-3.

Table-3: Classification of BPC challenges in ESI

\begin{tabular}{|c|c|c|c|c|c|}
\hline Categories & Managerial & Functional & $\begin{array}{c}\text { Inter- } \\
\text { organisational }\end{array}$ & Environmental & $\begin{array}{l}\text { Human } \\
\text { issues }\end{array}$ \\
\hline $\begin{array}{l}\text { Clarification and } \\
\text { understanding }\end{array}$ & $\checkmark$ & & & & $\checkmark$ \\
\hline Efficiency & $\checkmark$ & $\checkmark$ & & & \\
\hline Interoperability & $\checkmark$ & $\checkmark$ & $\checkmark$ & & \\
\hline Quality assurance & $\checkmark$ & $\checkmark$ & & & \\
\hline $\begin{array}{l}\text { Data and business } \\
\text { process sharing }\end{array}$ & $\checkmark$ & & $\checkmark$ & $\checkmark$ & $\checkmark$ \\
\hline Governance & $\checkmark$ & & $\checkmark$ & & \\
\hline Risk & $\checkmark$ & & & & \\
\hline $\begin{array}{l}\text { Economic conditions and } \\
\text { cost }\end{array}$ & $\checkmark$ & & & $\checkmark$ & \\
\hline Complexity & $\checkmark$ & $\checkmark$ & & & $\checkmark$ \\
\hline Inter-dependencies & $\checkmark$ & & $\checkmark$ & & \\
\hline $\begin{array}{l}\text { Autonomy and } \\
\text { Confidentiality }\end{array}$ & & & $\checkmark$ & $\checkmark$ & $\checkmark$ \\
\hline Monitoring & $\checkmark$ & & & & $\checkmark$ \\
\hline Standardisation & $\checkmark$ & $\checkmark$ & & $\checkmark$ & \\
\hline Agility and flexibility & & $\checkmark$ & & & $\checkmark$ \\
\hline Politics & & & & $\checkmark$ & $\checkmark$ \\
\hline
\end{tabular}


People related challenges

(e.g. commitment,

resistance, culture

changing, etc.)

As represented in Table-3, all challenges can be mapped to a particular category, which in the table are labelled by a Tick mark $(\checkmark)$. However, some of them are also related to other dimensions. It means they can be addressed by success factors, which are developed and available in other BPC dimensions. For example, "data and business process sharing" is logically and principally categorised in the inter-organisational category, but it is related to managerial, environmental, and human issues dimensions, as well. Therefore, the relevant blocks in the table are specified by a dotted Tick mark $(\checkmark)$.

Using this categorisation, Table-4 represents the BPC challenges along with their categories and a brief description of their practices. 
Table-4: BPC challenges in ESI

\begin{tabular}{|c|c|c|}
\hline \multicolumn{2}{|c|}{ BPC challenges } & Practices \\
\hline \multirow{5}{*}{ 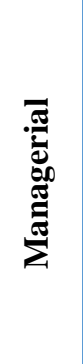 } & $\begin{array}{c}\text { Clarification and } \\
\text { understanding }\end{array}$ & $\begin{array}{l}\text { Analysing, understanding, assessing, and clarification of business } \\
\text { processes and BPC for internal departments and external partners }\end{array}$ \\
\hline & BPC Monitoring & High control, tracking, monitoring \& measuring of BPC during ESI \\
\hline & Risk & Analysis and management of the risk during BPC \\
\hline & Governance & Management of BPC (Main challenge in BPC) \\
\hline & Standardisation & $\begin{array}{l}\text { Standardisation of business processes, compliance of BPC with business } \\
\text { standards, policies and regulations }\end{array}$ \\
\hline \multirow{4}{*}{ 预 } & Efficiency & $\begin{array}{l}\text { Improving efficiency and reducing redundancies and time lags in business } \\
\text { processes }\end{array}$ \\
\hline & $\begin{array}{l}\text { Quality } \\
\text { assurance }\end{array}$ & $\begin{array}{l}\text { Preventing any error and enhancing the quality of BPC and redesigned } \\
\text { business processes }\end{array}$ \\
\hline & Complexity & $\begin{array}{l}\text { Reducing the complexity of business processes especially when performed } \\
\text { by various partners }\end{array}$ \\
\hline & $\begin{array}{l}\text { Agility \& } \\
\text { Flexibility }\end{array}$ & $\begin{array}{l}\text { Providing agility and flexibility for business processes to quickly response } \\
\text { to continuous change }\end{array}$ \\
\hline \multirow{4}{*}{ 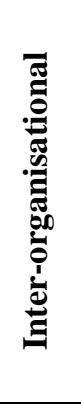 } & Interoperability & $\begin{array}{c}\text { Enhancing inter-operation and inter-coordination between business } \\
\text { processes across different departments and organisations }\end{array}$ \\
\hline & $\begin{array}{c}\text { Data and } \\
\text { business process } \\
\text { sharing }\end{array}$ & $\begin{array}{l}\text { Convincing parties to share necessary data and the activities of processes } \\
\text { with each other, in both intra- and inter-organisational BPC }\end{array}$ \\
\hline & $\begin{array}{c}\text { Inter- } \\
\text { dependencies }\end{array}$ & Inter-dependencies between processes, departments, and stakeholders \\
\hline & $\begin{array}{l}\text { Autonomy and } \\
\text { Confidentiality }\end{array}$ & $\begin{array}{l}\text { Autonomy and confidentiality of external partners for inter-organisational } \\
\text { business processes }\end{array}$ \\
\hline \multirow{2}{*}{ : } & $\begin{array}{c}\text { Economic } \\
\text { conditions and } \\
\text { cost of change }\end{array}$ & Cost reduction in the process of BPC \\
\hline & Politics & $\begin{array}{l}\text { Organisational power, formal and informal relations, and communication } \\
\text { between staff, management, and BPC project leaders }\end{array}$ \\
\hline 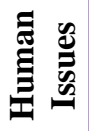 & $\begin{array}{l}\text { People related } \\
\text { challenges }\end{array}$ & $\begin{array}{l}\text { Minimising human issues in BPC, such as people acceptance, } \\
\text { commitment, culture changing, knowledge of the users and stakeholders }\end{array}$ \\
\hline
\end{tabular}

Based on the details provided in Table- 4 and discussion of success factors in section 3 , a conceptual framework for addressing BPC challenges in ESI is developed and shown in Figure-4. 


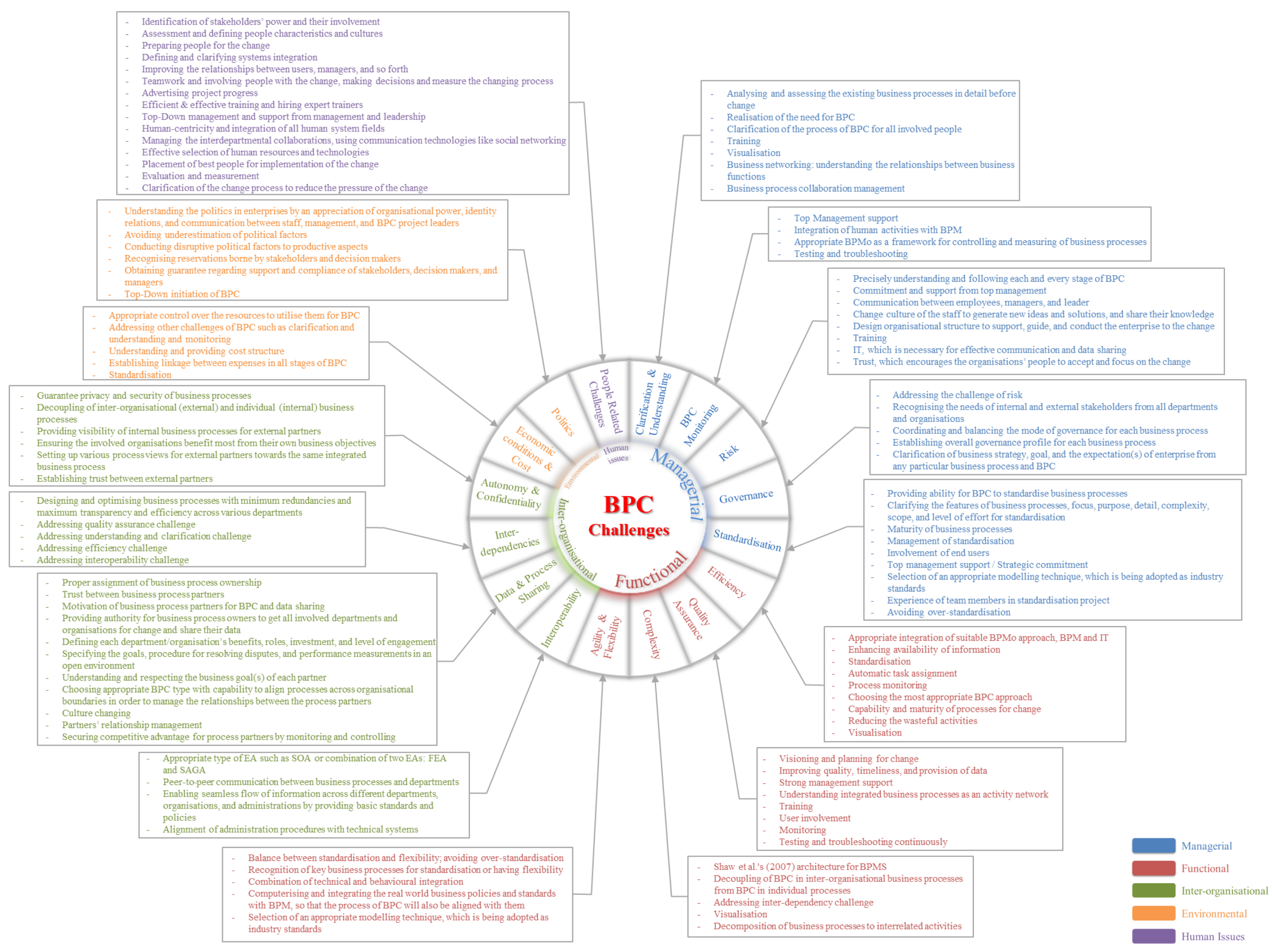

Figure-4: A conceptual framework for addressing BPC challenges in ESI 
The above framework integrates the most significant findings of earlier researchers and comprehensively signifies BPC challenges in ESI. In addition, it highlights some practices, success factors, and techniques to overcome the BPC challenges and conducting a successful BPC for systems integration. Different categories of BPC challenges, which were identified in this study, have been specified by different colours, so that their success factors, tools and techniques have also been mentioned in the same category. However, these are some success factors exemplars, suggested and tested by various organisations. New success factors, approaches, tools, and techniques can be added to the framework based on the findings of future research/experiments. The framework will also be useful to be applied in various contexts including the public sector, such as E-government, smart city development, and so forth, which require systems integration. This application allows adapting the success factors, approaches, and techniques learned from the ESI context for newly developed contexts. Improving the practices by applying and testing innovative success factors, will also create best practices for addressing BPC challenges in any context (Bardach, 2011). This makes the framework dynamic and adaptable for the related contexts.

\section{Conclusions}

By emphasising the two facts that BPC is a key element of ESI and several BPC challenges have been faced and attempted to be addressed since the 1990s; this research identified 16 BPC challenges in ESI and suggested some approaches and success factors for addressing them. It was carried out through a comprehensive literature analysis along with qualitative validation of the findings through unstructured interviews. This process offered a list of empirically validated BPC challenges and success factors, tools, techniques, and approaches for addressing them. Next, by adopting Kettinger and Grover's (1995) BPC model, BPC challenges in ESI were categorised into five categories of managerial, interorganisational, environmental, functional, and human issues. Accordingly, the study produced a unified list of BPC challenges and a conceptual framework for addressing BPC challenges in the ESI context.

\subsection{Contributions}

The research contributed to the body of academic knowledge by providing implications and usefulness for both theory and practice (e.g. addressing BPC challenges in firms and government agencies) in the following ways:

- Theoretical contributions:

- Identifying and presenting the BPC challenges in ESI using qualitative survey, including literature analysis and semi-structured interviews and proposing some success factor exemplars;

- Categorising the BPC challenges into five categories of managerial, functional, interorganisational, environmental, and human issues, based on the BPC challenges' 
characteristics, and using adoption and various qualitative analysis strategies, including coding, thematic analysis, theoretical and organisational categorisation, and connecting strategy;

- Practical contributions:

- The conceptual framework will be utilised to develop similar frameworks for conducting BPC in any other related contexts, in which systems integration is required (e.g. smart city development), in order to design their systems integration roadmap, based on an understanding of BPC challenges and their success factors, offered by the findings of this research;

- The conceptual framework helps the industry to develop solutions and tools for effective and efficient BPC, based on the suggested success factors and techniques for the BPC challenges; and

- The conceptual framework will act as a guideline for categorisation and resolution of the BPC challenges in any organisation.

\subsection{Limitations}

Although every effort has been taken to minimise the weaknesses, some limitations of this research should be noted. Like any qualitative study, in which the interviews are undertaken, the information gathered through interviews, firstly, relies on the participants' experience of facing BPC challenges and utilising success factors during their ESI projects. In addition, the accuracy of data depends on the interviewee's remembrance of the occasions that they have faced the BPC challenges and have attempted to overcome them. Moreover, the amount and quality of data are influenced by the interviewees' reluctance to share, due to the rational that such information belongs to their own organisation and sharing the information may cause problems for them. When such situations were experienced, the interviewer assured the participants that all collected data will remain anonymous, meaning that both interviewees' and organisations' names will not be revealed. In addition, the interviewer and other members of the research team has no affiliations to the participants' organisations.

Secondly, the accuracy of the gathered data, is dependant on understanding and interpretation of the researcher during literature analysis, interviews, and throughout the analysis of data. As explained in section 2 , the researcher attempted to minimise this limitation by utilising intercoder reliability approach and comparison of the results, as well as immediate verification of the interview findings with the participants in every interview.

\subsection{Recommendations and further research}

This study served as a base to elucidate the success factors for BPC in ESI. The new study prospects released from these results are recommended to transform the identified success factors and practices 
to new approaches and technical/practical tools for effective BPC in ESI. In other words, every success factor code, which is appeared in the conceptual framework, should be analysed, extended, converted, or linked to implementable tools, techniques, and approaches to be practically implemented. Existing tools and techniques such as BPR, BPMo, WfM, Six Sigma, and so forth can be utilised for this purpose. In addition, continuous research on enhancing the success factors for addressing BPC challenges in ESI is recommended. Furthermore, the study elucidated the systems integration domain in enterprises, focusing on its BPC aspect. Thus, future directions of research would be concentrated on the technical and social aspects of ESI. Feasibly, similar frameworks can be developed to guide enterprise and solution providers for their ESI projects.

\section{References}

Al-Mashari M, Al-Mudimigh A and Zairi M (2003) Enterprise resource planning: A taxonomy of critical factors. European Journal of Operational Research 146(2): 352-364.

Bardach E (2011) Practical Guide for Policy Analysis: The Eightfold Path to More Effective Problem Solving. SAGE Publications.

Braganza A and Lambert R (2000) Strategic integration: developing a Process-Governance Framework. Knowledge and Process Management 7(3): 177-186.

Buh B, Kovačič A and Indihar Štemberger M (2015) Critical success factors for different stages of business process management adoption - a case study. Economic Research-Ekonomska Istraživanja 28(1). Sveučilište Jurja Dobrile u Puli, Odjel za ekonomiju i turizam 'Dr. Mijo Mirković': 243-258.

Carey A (2001) Effective risk management in financial institutions: the turnbull approach. Balance Sheet 9(3). MCB UP Ltd: 24-27.

Chalmeta R and Pazos V (2015) A step-by-step methodology for enterprise interoperability projects. Enterprise Information Systems 9(4). Taylor \& Francis: 436-464.

Chen D, Doumeingts G and Vernadat F (2008) Architectures for enterprise integration and interoperability: Past, present and future. Computers in Industry 59(7): 647-659.

Chen Q and Hsu M (2001) Inter-enterprise collaborative business process management. In: Proceedings 17th International Conference on Data Engineering, 2001, pp. 253-260. IEEE Comput. Soc.

Cochran J and Gupta S (2017) Business-Driven Information Systems Change: Establishing an Alternate Lens for Understanding the Change Process. AMCIS 2017 Proceedings.

Committee on Human-System Design Support for Changing Technology, Committee on Human Factors, Board on Human-Systems Integration, et al. (2007) Human-System Integration in the System Development Process: A New Look. Washington DC: National Academies Press.

Creswell JW (2009) Research Design: Qualitative, Quantitative, and Mixed Methods Approaches. Los Angeles, London, New Delhi, Singapore: SAGE Publications.

Dalal NP, Kamath M, Kolarik WJ, et al. (2004) Toward an integrated framework for modeling enterprise processes. Communications of the ACM 47(3). ACM: 83-87.

Davenport TH, Harris JG and Cantrell S (2004) Enterprise systems and ongoing process change. Business Process Management Journal 10(1). Emerald Group Publishing Limited: 16-26. 
de Albuquerque JP and Christ M (2015) The tension between business process modelling and flexibility: Revealing multiple dimensions with a sociomaterial approach. The Journal of Strategic Information Systems 24(3). North-Holland: 189-202.

Dufresne T and Martin J (2003) Process modeling for e-business. INFS 770 - Methods for Information Systems Engineering: Knowledge Management and E-Business: 1-28.

Ehie IC and Madsen M (2005) Identifying critical issues in enterprise resource planning (ERP) implementation. Computers in Industry 56(6): 545-557.

Ferreira DMR and Ferreira JJP (2005) Towards a workflow-based integration architecture for business networking. Business Process Management Journal 11(5). Emerald Group Publishing Limited: $517-531$.

Finney S and Corbett M (2007) ERP implementation: a compilation and analysis of critical success factors. Business Process Management Journal 13(3). Emerald Group Publishing Limited: 329_ 347.

Fosso Wamba S, Kala Kamdjoug JR, Akter S, et al. (2018) ERP Adoption and Use in Production Research: An Archival Analysis and Future Research Directions. Springer, Cham, pp. 539-556.

Grabot B, Mayère A and Bazet I (2008) ERP Systems and Organisational Change: A Socio-Technical Insight. Springer London; 1 edition.

Grabowski M and Roberts KH (2006) Risk Mitigation in Virtual Organizations. Journal of ComputerMediated Communication 3(4).

Grover V and Kettinger WJ (1995) Business Process Change: Concepts, Methods, and Technologies. Idea Group Inc (IGI).

Grover V, Jeong SR, Kettinger WJ, et al. (1995) The implementation of business process reengineering. Journal of Management Information Systems 12(1). M. E. Sharpe, Inc.: 109-144.

Guijarro L (2007) Interoperability frameworks and enterprise architectures in e-government initiatives in Europe and the United States. Government Information Quarterly 24(1): 89-101.

Guo X, Sun SX and Vogel D (2014) A Dataflow Perspective for Business Process Integration. ACM Transactions on Management Information Systems 5(4). ACM: 1-33.

Gureva MA, Kirillov A V, Vinichenko M V, et al. (2016) International Review of Management and Marketing Special Issue on \&quot;Management of Systems of Socio-Economic and Legal Relations in Modern Conditions of Development of Education and Society\&quot; Management of Innovations and Innovative Process: Concept, Essence, Classification and Diffusion. International Review of Management and Marketing |6(S6): 147-153.

Hammer M and Champy J (1993) Reengineering the Corporation: A Manifesto for Business Revolution. New York: Harper Business.

Harmon P (2003) Business Process Change: A Manager's Guide to Improving, Redesigning and Automating Processes. San Francisco: Morgan Kaufmann Publishers.

Harmon P (2019) Business Process Change: A Business Process Management Guide for Managers and Process Professionals. Fourth. Birtcher K and Lawrence L (eds). Cambridge, Malden: Morgan Kaufmann Publishers.

Hendricks KB, Singhal VR and Stratman JK (2007) The impact of enterprise systems on corporate performance: A study of ERP, SCM, and CRM system implementations. Journal of Operations Management 25(1): 65-82.

Herath SK and Gupta A (2013) Towards Increasing the Management Accountants' Contribution to the Changing Organizational Needs: A Framework for Analysing Cost Structures in Business 
Process Reengineering (BPR). Proceedings of International Conference on Business Management.

Hernández González A, Calero C, Pérez Parra D, et al. (2019) Approaching Green BPM characterisation. Journal of Software: Evolution and Process 31(2). John Wiley \& Sons, Ltd: e2145.

Hull R and Motahari Nezhad HR (2016) Rethinking BPM in a Cognitive World: Transforming How We Learn and Perform Business Processes. Springer, Cham, pp. 3-19.

Hvolby H-H and Trienekens JH (2010) Challenges in business systems integration. Computers in Industry 61(9): 808-812.

Jarrar YF, Al-Mudimigh A and Zairi M (2000) ERP implementation critical success factors-the role and impact of business process management. In: Proceedings of the 2000 IEEE International Conference on Management of Innovation and Technology. ICMIT 2000. 'Management in the 21st Century' (Cat. No.00EX457), 2000, pp. 122-127. IEEE.

Javidroozi V, Shah H, Cole A, et al. (2015) Towards a City's Systems Integration Model for Smart City Development: A Conceptualization. In: 2015 International Conference on Computational Science and Computational Intelligence (CSCI), December 2015, pp. 312-317. IEEE.

Javidroozi V, Shah H, Amini A, et al. (2016) Business process change: A guide for implementers. In: Proceedings of the International Conference on e-Learning, e-Business, Enterprise Information Systems, and e-Government (EEE), 2016, pp. 93-99.

Jurisch MC, Ikas C, Palka W, et al. (2012) A Review of Success Factors and Challenges of Public Sector BPR Implementations.

Jurisch MC, Palka W, Wolf P, et al. (2014) Which capabilities matter for successful business process change? Business Process Management Journal 20(1). Emerald Group Publishing Limited: 4767.

Kettinger WJ and Grover V (1995) Toward a theory of business process change management ProQuest. Journal of Management Information Systems 12(1): 9.

Kettinger WJ, Teng JTC and Guha S (1997) Business process change: A study of methodologies, techniques, and tools - ProQuest. MIS Quarterly 21(1): 55-80.

Klischewski R (2004) Information integration or process integration? How to achieve interoperability. In: Proceedings EGOV 2004, Zaragoza, 2004, pp. 57-65. Springer Berlin Heidelberg.

Knights D and McCabe D (1998) When 'Life Is but a Dream': Obliterating Politics Through Business Process Reengineering? Human Relations 51(6): 761-798.

Kobayashi T, Tamaki M and Komoda N (2003) Business process integration as a solution to the implementation of supply chain management systems. Information \& Management 40(8): 769780.

Korhonen J (2007) Requisite Control Structure in BPM Governance. In: 1st International Workshop on BPM Governance-WoGo, 2007.

Kothari CR (2008) Research Methodology: Methods and Techniques. Delhi: New Age International.

Larsen MH and Klischewski R (2004) Process ownership challenges in IT-enabled transformation of interorganizational business processes. In: 37th Annual Hawaii International Conference on System Sciences, 2004. Proceedings of the, 2004, p. 11 pp. IEEE.

Legner C and Wende K (2007) 'The Challenges of Inter-organizational Business Process Design - a Res' by Christine Legner, et al. In: European Conference on Information Systems (ECIS 2007) (eds H Österle, J Schelp, and R Winter), 2007, pp. 1643-1654. 
Lewis M and Slack N (2003) Operations Management. Psychology Press.

Liu C, Li Q and Zhao X (2008) Challenges and opportunities in collaborative business process management: Overview of recent advances and introduction to the special issue. Information Systems Frontiers 11(3): 201-209.

Lohrmann M and Reichert M (2016) Effective application of process improvement patterns to business processes. Software \& Systems Modeling 15(2). Springer Berlin Heidelberg: 353-375.

Madni MA (2011) Integrating Humans With and Within Complex Systems: Challenges and Opportunities. CrossTalk: The journal of Defence Software Engineering: 4-8.

Markus ML and Jacobson DD (2010) Business Process Governance. In: vom Brocke J and Rosemann M (eds) Handbook on Business Process Management 2. Berlin, Heidelberg: Springer Berlin Heidelberg, pp. 201-222.

Markus ML and Jacobson DD (2015) Handbook on Business Process Management 2. vom Brocke J and Rosemann M (eds). Berlin, Heidelberg: Springer Berlin Heidelberg.

Maxwell JA (2008) Designing a qualitative study. In: The SAGE Handbook of Applied Social Research Methods. Los Angeles, London, New Delhi, Singapore, Washington DC: SAGE Publications, pp. 214-253.

Momoh A, Roy R and Shehab E (2010) Challenges in enterprise resource planning implementation: state-of-the-art. Business Process Management Journal 16(4). Emerald Group Publishing Limited: 537-565.

Morton NA and Hu Q (2008) Implications of the fit between organizational structure and ERP: A structural contingency theory perspective. International Journal of Information Management 28(5): 391-402.

Motwani J (2003) A business process change framework for examining lean manufacturing: a case study. Industrial Management \& Data Systems 103(5). MCB UP Ltd: 339-346.

Motwani J, Kumar A and Antony J (2004) A business process change framework for examining the implementation of six sigma: a case study of Dow Chemicals. The TQM Magazine 16(4). Emerald Group Publishing Limited: 273-283.

Motwani J, Subramanian R and Gopalakrishna P (2005) Critical factors for successful ERP implementation: Exploratory findings from four case studies. Computers in Industry 56(6): 529544.

Müller S, Mathiassen L, Saunders C, et al. (2017) Political Maneuvering During Business Process Transformation: A Pluralist Approach. Journal of the Association for Information Systems 18(3): 173-205.

Na Ranong P and Phuenngam W (2009) Critical Success Factors for effective risk management procedures in financial industries : A study from the perspectives of the financial institutions in Thailand. Umeå University.

Nah FF-H, Lau JL-S and Kuang J (2001) Critical factors for successful implementation of enterprise systems. Business Process Management Journal 7(3). MCB UP Ltd: 285-296.

Nah FF-H, Tan X and Teh SH (2004) An Empirical Investigation on End-Users' Acceptance of Enterprise Systems. Information Resources Management Journal 17(3). IGI Global: 32-53.

Omidi A (2016) Factors Affecting the Implementation of Business Process Reengineering: Taking into Account the Moderating Role of Organizational Culture (Case Study: Iran Air). Procedia Economics and Finance 36. Elsevier: 425-432.

Paim R and Flexa R (2011) Process Governance: Definitions and Framework, Part 1. 
Paris M and Thijs N (2003) Business Process Reengineering; or how to enable bottom-up participation in a top down reform programme. Leuven.

Pereira VR, Maximiano ACA and Diógenes de Souza Bido (2019) Resistance to change in BPM implementation. Business Process Management Journal ahead-of-p(ahead-of-print).

Puth G and Walt L van der (2012) Culture change or reengineering: A case study of employee perceptions preceding a major imminent change. African Journal of Business Management 6(47): 11626-11634.

Rinaldi M, Montanari R and Bottani E (2015) Improving the efficiency of public administrations through business process reengineering and simulation A case study. Business Process Management Journal.

Ritchie J and Lewis J (2003) Qualitative Research Practice: A guide for Social Science Students and Researchers.

Rosemann M and Bruin T De (2005) Towards a Business Process Mangement Maturity Model. ECIS 2005 Proceedings of the Thirteenth European Conference on Information Systems (May): 2628.

Rosenkranz C, Seidel S, Mendling J, et al. (2010) Business Process Management Workshops. Rinderle-Ma S, Sadiq S, and Leymann F (eds). Lecture Notes in Business Information Processing. Berlin, Heidelberg: Springer Berlin Heidelberg.

Scholl HJ (Jochen) (2004) Current practices in e-government-induced business process change (BPC). Digital Government Society of North America: 18.

Schubert P and Williams SP (2011) A framework for identifying and understanding enterprise systems benefits. Business Process Management Journal 17(5): 808-828.

Shang S and Seddon PB (2002) Assessing and managing the benefits of enterprise systems: the business manager's perspective. Information Systems Journal 12(4): 271-299.

Shaw DR, Holland CP, Kawalek P, et al. (2007) Elements of a business process management system: theory and practice. Business Process Management Journal 13(1). Emerald Group Publishing Limited: 91-107.

Sikdar A and Payyazhi J (2014) A process model of managing organizational change during business process redesign. Business Process Management Journal 20(6). Emerald Group Publishing Limited: 971-998.

Slack N, Chambers S and Johnston R (2009) Operations and Process Management: Principles and Practice for Strategic Impact. Prentice Hall/Financial Times.

Smeds R, Lavikka R, Jaatinen M, et al. (2015) Interventions for the Co-creation of Interorganizational Business Process Change. Springer, Cham, pp. 11-18.

Smith H and Fingar P (2006) Business Process Management: The Third Wave. Meghan Kiffer Pr.

Stickland F (1996) Business process change: A systems thinking perspective. World Futures 47(1). Taylor \& Francis Group : 69-77.

Sturdy GR (2010) Business Process Reengineering: Strategies for Occupational Health and Safety. Cambridge Scholars Pub.

Swink M and Schoenherr T (2015) The Effects of Cross-Functional Integration on Profitability, Process Efficiency, and Asset Productivity. Journal of Business Logistics 36(1): 69-87.

Trkman P (2010) The critical success factors of business process management. International Journal of Information Management 30(2): 125-134. 
Vaughan PJ (2001) System Implementation Success Factors: It Is Not Just the Technology. University of Colorado. Colorado.

Vergidis K, Tiwari A and Majeed B (2008) Business Process Analysis and Optimization: Beyond Reengineering. IEEE Transactions on Systems, Man, and Cybernetics, Part C (Applications and Reviews) 38(1): 69-82.

Volkoff O, Strong DM and Elmes MB (2005) Understanding enterprise systems-enabled integration. European Journal of Information Systems 14(2). Nature Publishing Group: 110-120.

Vom Brocke J and Mendling J (2018) Business Process Management Cases : Digital Innovation and Business Transformation in Practice.

Weerakkody V and Currie W (2003) Integrating Business Process Reengineering with Information Systems Development: Issues \& Implications. In: BPM 2003 (ed. van der Aalst et al), Heidelberg, 2003, pp. 302-320. Springer-Verlag.

Weißbach R, Kirchner K, Reher F, et al. (2017) Challenges in Business Processes Modeling - Is Agile BPM a Solution? Springer, Cham, pp. 157-167.

Xu L Da (2011) Enterprise Systems: State-of-the-Art and Future Trends. IEEE Transactions on Industrial Informatics 7(4). IEEE: 630-640. 